\title{
EVOLUÇÃO DA EXPLORAÇÃO AGRICOLA NO RIO GRANDE DO SUL
}

Vera Maria Favila Miorin

Departamento de Geociências. Centro de Ciências Naturais e Exatas. UFSM. Santa Maria, RS.

RESUMO

Os estudos geogräficos do espaço rural nos ūltimos anos es tão direcionados, sobretudo, à organização agrāria.

Este trabalho, aborda o processo de ocupação do territōio sul-rio-grandense tentando captar a dinâmica da organização espacial através da anālise da evolução agrícola do Estado.

As relações advindas do meio natural e do processo histó rico, são apreendidas como elementos determinantes das transformações estruturais e conjunturais que se estabeleceram nos ūltimos anos, se parando o "Velho Rio Grande" do "Rio Grande de Hoje".

\section{SUMMARY}

MIORIN, V.M.F., 1983. Evolution of Agriculture Exploration in Rio Grande do Sul. Ciêneia e Natura, 5:45-58.

The geographical studies of rural space in recent years are above all directed towards agrarian organization.

The present work approaches the question of the process of accupation of the territory of Rio Grande do Sul trying to capture the dynamics of space organization through an analysis of the evolution of agriculture in the State.

The relationship that results from the natural environment and from the historical process are understood as determinant elements of the structural and conjuntural transformations that were estabilished in recent years, separating the 01d Rio Grande from the New Rio Grande.

INTRODUÇÃO

0 estado do Rio Grande do Sul, por se constituir de uma área que apresenta um setor agrīcola intensificado, tem servido co mo laboratório para estudos da evolução da exploração agrỉcola do País. Assim, as investigações realizadas no comportamento da agricul tura e pecuāria das mais diferentes āreas, permitem a detectação da evolução da exploração agrīcola a nîvel de região.

A porção norte do espaço gaūcho, considerada como ārea de agricultura e pecuāria tradicional, em estudos efetuados atē a déca da de 70, vem sofrendo uma evolução capaz de permitir a determinação dos indicadores de modernização da agricultura e a caracterização da modernização no conjunto da evolução da exploração agrícola do Esta do. 


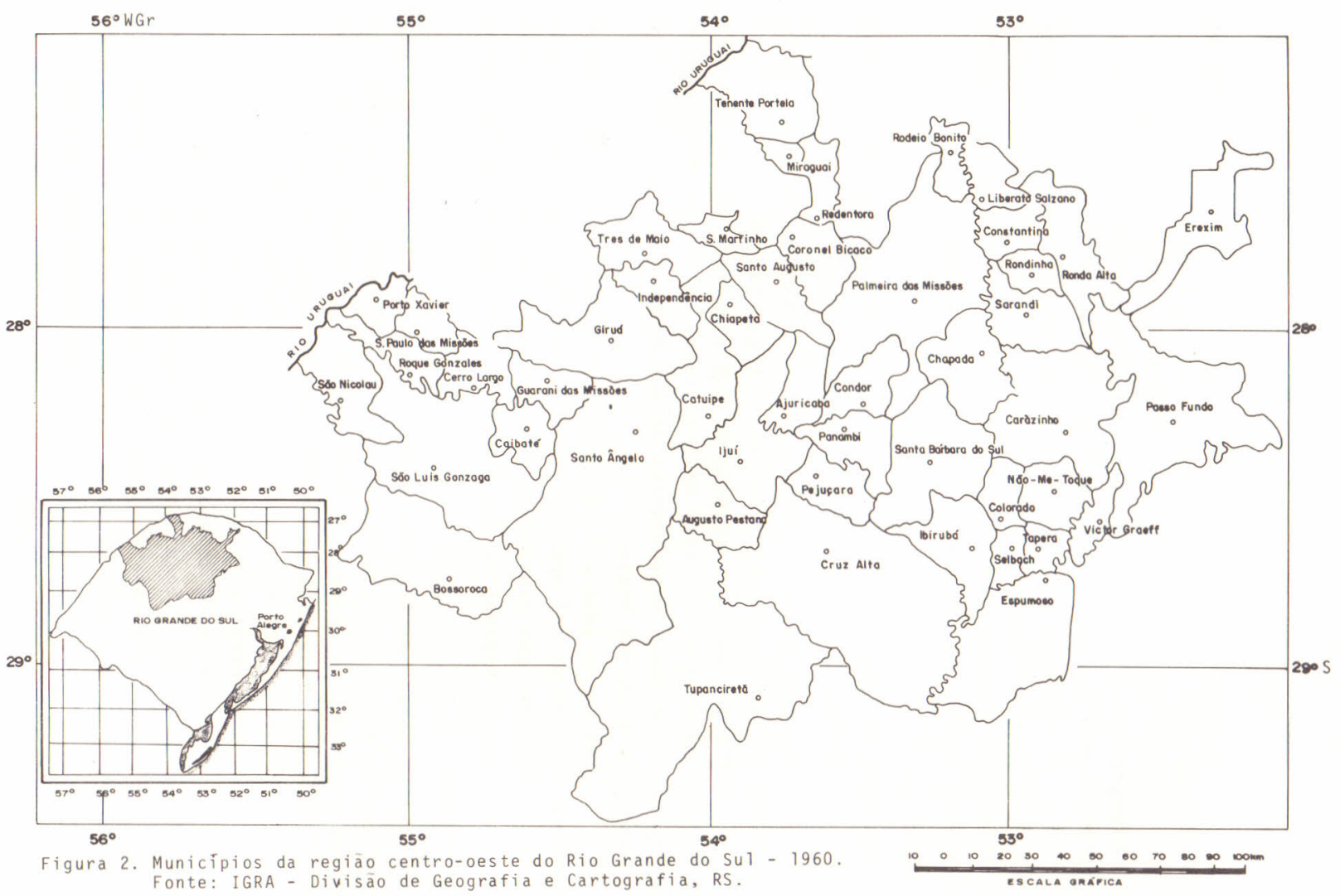




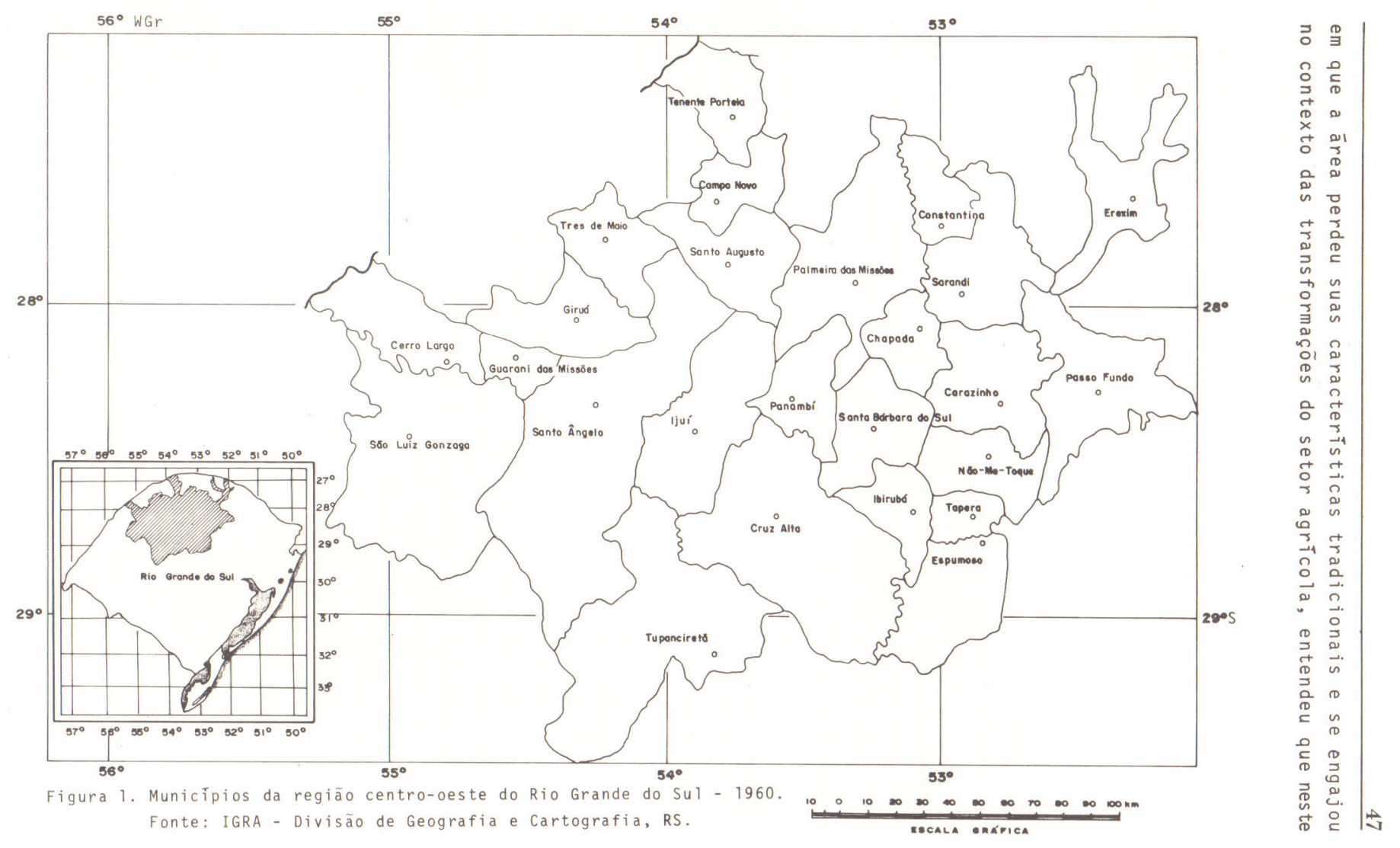


intervalo se viabilizaram as mudanças de organização do espaço agrā rio. Acredita-se ter sido este period, o que apresentou as mudanças mais bruscas na sociedade ruràl da ārea.

As cidades consideradas pacatas e de feições coloniais, as sistiram a um rápido processo de urbanização. Levas de ex-rurali $\underline{s}$ tas, deixando o campo, acomodaram-se nas āreas periféricas das cidá des quando não se deslocaram para as capitais regionais e para as "Grandes Cidades".

Esta ārea, onde a agricultura e a pecuária tradicional se caracterizam por mudanças, corresponde, tambēm, à ārea dos municípios que formam as zonas chamadas Regiões Fisiográficas das Missões, A to Uruguai e Planalto Médio.

Na falta de uma denominação jā existente, capaz de repre sentar todo o conjunto dos municípios que compõem a região selecio nada para que nela se efetuassem os estudos, optou-se pela denomina ção de região Centro-Noroeste do Estado do Rio Grande do Sul.

A OCUPAÇÃO DO ESPAÇO NO RIO GRANDE DO SUL

As características da agricultura gaūcha manifestam-se atra vēs do reconhecimento das formas de ocupação e de exploração da tẹ ra no Estado. 0 relacionamento dessas formas com o processo de explo ração agrāria adotado no Brasil, auxilia o entendimento de determi nados fatos que encontraram palco nesta porção meridional do País.

0 tipo de colonização estabelecida pela Coroa Portuguesa, comprometida com a garantia de permanēncia da posse da área e da ex ploração das riquezas tropicais e subtropicais, constituiu o ambien te rural brasileiro. A colonização tambēm contribuiu para que se de lineasse uma performance agrícola, constituída de grandes proprieda des ocupadas, principalmente, com atividades monocultoras, seja com a cana-de-açūcar no Nordeste (durante o Período Colonial), seja com - café no leste (no Período Imperial e Republicano).

0 Rio Grande do Sul, por sua situação geográfica, afasta do da Metrópole e por ter constituído, até o sēculo XVIII, uma ver dadeira "terra de ninguém", entre os domínios de Castela e Portugal, apresenta, em sua formação econōmica, características muito diferen tes das que são comuns ao resto do País, como bem define SCHILLING (5).

A introdução do Rio Grande do Sul, sua formação e seu pọ voamento no contexto português, teve início com a posse do Litoral e a conquista do Territörio Missioneiro que se constituiram em dois grandes marcos iniciais da ocupação do espaço sul-rio-grandense.

A posse do Litoral foi uma conquista lenta, iniciada em um primeiro momento nas expedições portuguesas que faziam reconhecimen 
to na costa sul da América até a altura do estuārio do Prata e, num segundo momento, com as doações de sesmarias em direção sul de Lagu na (SC), buscando as fronteiras do Rio da Prata.

As sesmarias contribuiram para o estabelecimento de gran des propriedades que se fortaleceram diante de uma topografia, uma vegetação e, na presença do gado bovino que possibilitaram a forma ção de estâncias; no princípio, ao longo do Litoral e que, mais tar de, foram se interiorizando enquanto encontraram continuidade de con dições.

No oeste do futuro territōrio do Rio Grande do Sul, às mar gens orientais do rio Uruguai, em terras de domínio espanhōl e sị tuadas ao norte da desembocadura do rio Ibicuí, surgem os Sete Povos das Missões como resultado e sîntese do trabalho de aldeamento e ca tequese dos jesuítas.

Deste trabalho resultou uma incipiente integração social de nosso territōrio, com a ordenação da vida humana sob o ponto de vista econômico, e o florescimento de nossa embrionäria civilização caracterizada pela criação de gado, pela agricultura de subsistên cia, pela presença de um processo industrial em formação e pelo co mércio da erva-mate.

Esta civilização, que se formava tanto no Litoral como no Deste e que, em seu alvorecer reunia em seu bojo elementos diversos, teve muitas vezes sua organização comprometida pelas investidas dos espanhōis vindo de oeste e sul e dos mamelucos bandeirantes vindos de leste e norte, porém todos eles, orientados, na maioria das vezes, pelas decisões político-administrativas das coroas de Portu gal e Espanha.

A despeito das interrupções sofridas pela embrionāria ci vilização sul-rio-grandense, as sesmarias permitiram que o povoamen to ultrapassasse os limites litorâneos, a que estava até então con finada, indo em direção ao baixo curso do rio jacuí. Neste procedi mento de multiplicação das estâncias em que o povoamento avançava pa ra o Interior, tiveram origem pequenas povoações surgidas em diferen tes locais. Sem obedecer a nenhum plano os pequenos núcleos (embriões urbanos) apresentavam, como característica primordial, o isolamento. Assim iniciou o desenvolvimento do chamado "Continente do Rio Gran de" a partir de 1737 .

Apesar de as Missões não apresentarem mais o aspecto de prosperidade de alguns anos antes, em consequência das lutas sofri das, mais tarde, apōs 1801, os luso-brasileiros implantaram cidades nos locais das antigas reduções que ressurgiram na forma de cidades povoadas por soldados licenciados do serviço militar. Estes reati varam os novos estabelecimentos, refizeram as lavouras e reuniram no 
vamente 0 gado em estâncias.

Em continuidade à ocupação do espaço no RS, que iniciou muito antes de seu estabelecimento como territōrio português, vamos encontrar uma nova investida polītico-estratēgica a partir de 1742 caracterizada pela colonização sistemātica engendrada pela Coroa Por tuguesa. Ao trazer casais de açorianos, buscava-se atingir os obje tivos que eram os de estabelecer a garantia da posse das fronteiras meridionais e a criação de um povoamento mais concentrado sob a égi de da agricultura. Para o Rio Grande do Sul, o encaminhamento dos ilhēus dos arquipēlagos de Açores, Cabo Verde e outros, representou uma contribuição da coroa Portuguesa ao povoamento e à ocupação do territōrio sul-rio-grandense.

As novas doações passaram a ter como dimensão $1 / 4$ de $1 \underline{e}$ gua em quadro para que nela fosse principiada a lavoura. Este novo critério de estrutura fundiāria adotado caracterizava a urgência que tinha Portugal em consolidar a posse da terra além do Meridiano es tipulado no Tratado de Tordesilhas.

Por volta de 1750, chegaram no Rio Grande do Sul cerca de quatrocentos casais provenientes dos Açores. Ao distribuirem-se pe 10 Litoral e penetrarem pelo vale dos rios Jacuỉ e Taquari, fundaram povoações que deram origem à cidades.

0 não cumprimento das promessas feitas pela Coroa Portu guesa fez com que os açorianos (assim denominados regionalmente) se localizassem ao longo das povoações fundadas e, com o tempo, se tor nassem prósperos fazendeiros dedicados à criação de gado.

Este comportamento da Coroa Portuguesa, em relação aos ilhēus e ao Rio Grande do Sul, além de traduzir uma ocupação geopo lítica, viabilizava a atividade econômica centrada na criação de bo vinos jā existentes nas estâncias e nas propriedades organizadas pe los açorianos.

Esta diferença de objetivos na ocupação de āreas desenvol vidas pela polîtica de posse dos portugueses em relação ao sul da colōnia da Amērica, somada às condições favorāveis e à imensição de vazio demogrāfico em uma zona de fronteiras-vivas (domīnio de Portu gal e Espanha), vem explicar a variação do tamanho da propriedade no Rio Grande do Sul e sua diferença em relação às demais regiões do Pais.

Serā ainda o objetivo de consolidação da posse das frontei ras que nortearā a dimensão das colōnias e caracterizará a fase da colonização germānica e italiana.

0 alvorecer do Impērio do Brasil foi palco da segunda in ciativa de povoamento intenso e sistemático no Rio Grande do Sul com a introdução de colonos alemães (1824) e de italianos (1874). Forma 
ram-se, através deles, os dois grandes segmentos da imigração para - Estado. Eles impulsionaram a agricultura e deram inīcio à indús tria num avanço contínuo para o interior seguindo os vales fluviais da bacia hidrográfica do rio Jacuí; desmatando, lançando lavouras e criando colónias que evoluíram para cidades. Eles, posteriormente, povoaram a encosta do nordeste do Planalto Basáltico do Rio Grande do sul.

A imigração italiana coube o povoamento inicial de uma vas ta zona colonial localizada no norte e nordeste do Estado.

As propriedades distribuỉdas durante esta nova fase conhe ceram duas dimensões de superfïcie: em um primeiro momento, a ocupa ção das colônias caracterizou-se por uma divisão em 10 tes de 48 ha de superfīcie em média; no segundo momento, com a instalação de no vas colōnias, a superfície das propriedades que irā se formar será de 25 ha, permitindo algumas oscilações "entre 15 e 35 ha no máximo", como coloca ROCHE (4).

o processo imigratōrio no Rio Grande do Sul deixou, como consequência, no espaço gaúcho:

- 0 povoamento das āreas originalmente de matas no Estado.

- Um povoamento dinâmico a partir de São Leopoldo para a região da Encosta Inferior do Nordeste e que, por um processo de mul tiplicação da ocupação dos antigos núcleos coloniais, alcançou a En costa Superior do Nordeste e a região do Alto Uruguai.

- o desenvolvimento de um sistema de pequenas propriedades.

- A presença de um regime de exploração agrỉcola distan ciado dos processos modernos de técnicas agrícolas, devido às difí culdades e retardo no desenvolvimento da circulação como um todo.

Desta forma, solidificam-se no Estado as bases de uma es trutura agrária, delineada desde 1732 , centrado no predomínio da pro priedade privada e no uso da terra voltada para atividades de comér cio interno onde produtos, como o trigo, o arroz, o feijão, a ceva da, o milho, a batata, a mandioca e os demais produtos de horta e pomar fazem a fartura da mesa do colono. A criação de gado, represen tada em princípio pelo bovino e suíno, permitia inúmeras utilidades (carne, leite, banha, toucinho e couro).

Por outro lado, a variação da topografia sobre a variação do tamanho da propriedade e, consequentemente, no seu uso, criou pai sagens típicas. Entre estas paisagens podemos destacar duas como as que de certo modo generalizam o espaço gaūcho:

- A paisagem da pecuāria, na qual os jesuĩtas espanhōis ha viam introduzido o gado, e a consideravam como a melhor alternativa para a fixação das tribos nas reduções guaranĩs, que passou a ser o recurso bāsico de subsistência e fonte de divisas. A decorrência do 
sistema de grandes propriedades (a estāncia), relacionadas a uma to pografia plana e tendo como atividade econōmica a criação de gado, foi o resultado natural desta relação estabelecida entre o homem e o meio.

- A paisagem das colōnias, cobrindo espaços vazios e ace lerando a ocupação da terra, realizando o processo imigratório res ponsāvel pelo desenvolvimento da agricultura, valendo-se de novas formas de uso da terra e ocupando äreas de matas, formou-se nos espa ços preteridos pela pecuāria ensejando o desenvolvimento de proprie dades sobre um espaço topograficamente variāvel entre o ondulado e o movimentado (Figura 3 ).

E segundo esse quadro de ocupação do espaço que se organi zou uma estrutura de exploração agrāria de raízes profundamente ré lacionadas aos aspectos histōrico-polīticos e se explica o processo de modernizaçã்o que a agricultura do Estado e, em particular a da região centro-noroeste gaūcho, assume ao longo de sua evolução.

O PROCESSO DE MODERNIZAÇÃO DA AGRICULTURA NO RIO GRANDE DO SUL

A peculiaridade do processo de ocupação do espaço no Rio Grande do sul, devido ao afastamento dos centros hegemónicos de de cisão e a sua situação geográfica em relação às demais àreas do paîs, determinou um tipo de evolução agrícola que tem desempenhado uma fun ção significativa no conjunto da economia nacional.

No começo, época da formação econômica do País, o papel cumprido pelo Rio Grande do Sul foi tão distinto do conjunto colo nial que o próprio perīodo da colonização sistemática é entendido por historiadores como PRADO JR. (2) como "um sistema de colonizaçãoori ginal" no cenārio da colonização portuguesa da Amērica.

0 afastamento do centro econômico, a posição geopolîtica e o tipo de ocupação do espaço interferiram diretamente no modo de exploração agrāria do Estado.

A evolução do setor agrícola gaūcho deve ser considerada como decorrência do desenvolvimento da economia brasileira. Entre tanto este desenvolvimento econōmico pode ser dividido em dois perīo dos como recomenda a Fundação de Economia e Estatística do Rio Gran de do Sul em RIO GRANDE DO SUL (3): O primeiro periodo, anterior a 1955, é definido como a etapa de "expansão da produção de bens leves de consumo" a nível de economia nacional; o segundo período, após 1955, comandado pela "expansão do setor industrial produtor de bens durāveis de consumo".

Esta divisāo proposta pela FEE, alēm de entender a inter dependência entre o desenvolvimento agrícola e não-agrícola, deter mina uma evolução agrícola para o Rio Grande do Sul realizada à luz 


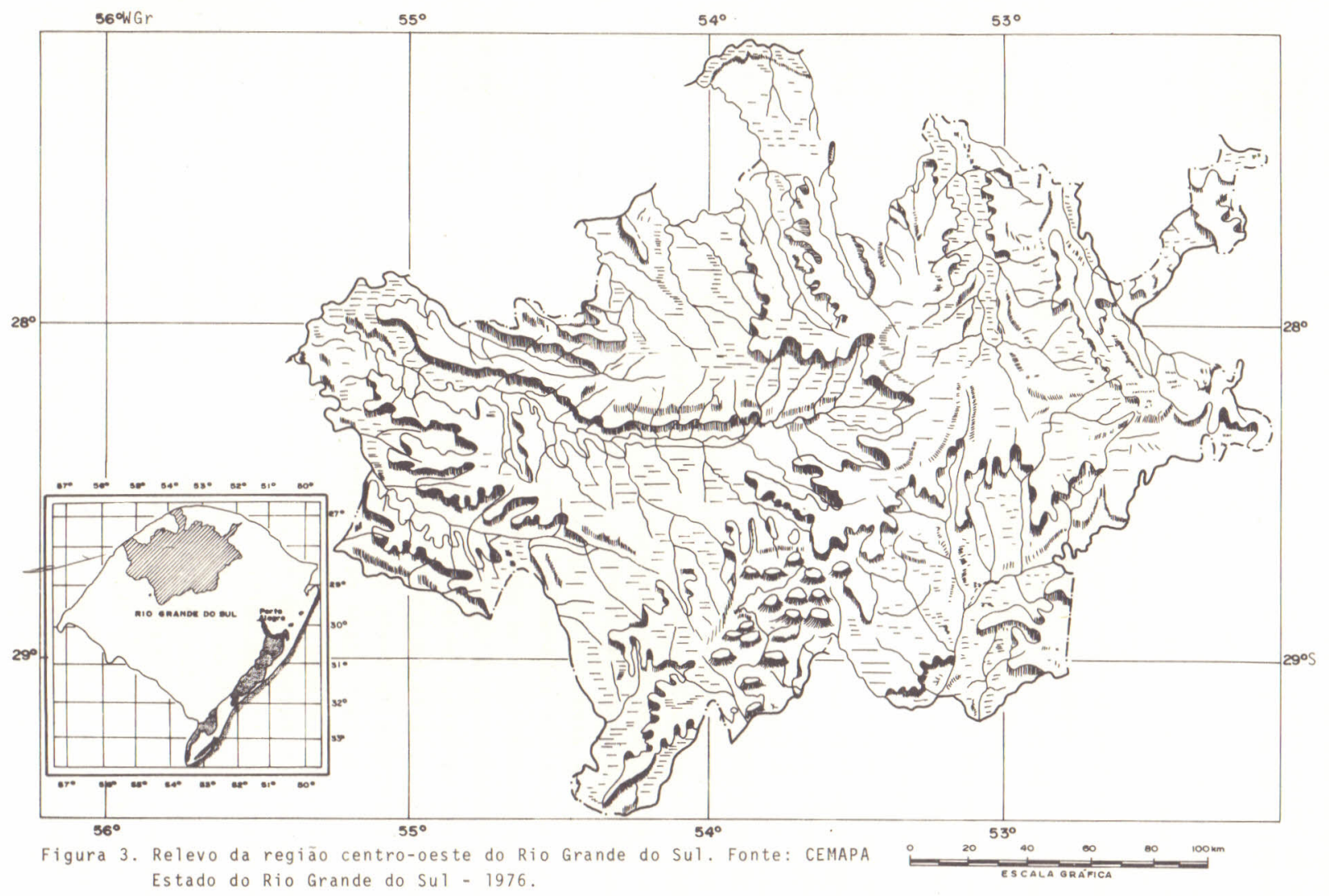

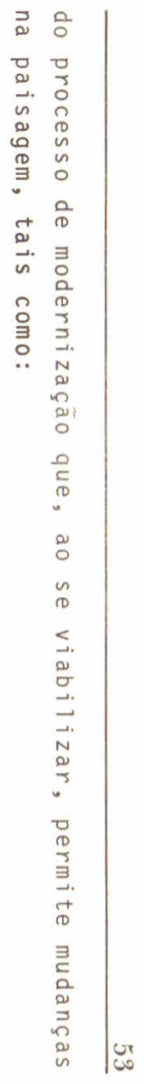


- Coexistência dos setores tradicional e moderno na agri cultura, tanto à nîvel de região como de produto. A maior importān cia de um ou outro setor depende do estāgio de desenvolvimento ecó nômico em que se encontra o paîs, já que a produção agrîcola depen de do crescimento do setor não -agrícola que se impõe como fator $1 \underline{i}$ mitativo do processo de modernização dos países em desenvolvimento.

- Os custos sociais decorrentes do ajustamento à nova tec nologia serão suportados pela mão-de-obra que se dirige ao mercado de trabalho urbano gerando, desta forma, maiores problemas sociais.

- o ajustamento do setor agrícola, ao modelo politico-eco nômico adotado a nível nacional.

0 primeiro período da economia nacional, caracterizado pe la produção de bens leves de consumo, no Rio Grande do Sul toma a forma de criação de gado e indūstria do charque (período das doações de sesmarias e da formação das estâncias). Com a vinda dos açoria nos e início do cultivo do trigo, surge a lavoura de carāter mercan til com comércio no centro do País. A posição do trigo como lavoura mercantil desaparece com a concorrēncia da farinha americana e o ataque da ferrugem, provocando a liquidação das propriedades agrĩco las então absorvidas pelas propriedades pastoris.

o reaparecimento da lavoura, que se coloca ao lado da pe cuāria tradicional, ocorre na fase da imigração alemã e italiana. A pecuāria tradicional, com um comportamento diferente, devido às mu danças impostas pelo surgimento das charqueadas, alia-se a uma lavou ra diversificada e ressurginte que ganha espaços no mercado do cen tro do País graças ao advento da cafeicultura.

A expansão dos cafezais sobre todas as āreas aproveitadas com culturas de subsistência, representou a possibilidade de assegu rar um mercado para os produtos coloniais do Rio Grande do Sul e, consequentemente, à continuidade da lavoura colonial. A expansão das culturas coloniais provocou crescimento no setor agrícola, alarga mento dos espaços para as colōnias européias no extremo-sul e incen tivo à entrada de novos imigrantes.

A viabilidade de comercialização e preços para os produ tos oriundos do setor agrícola permitiram que o setor não-agrícola do Estado conhecesse uma fase de criação e evolução, entusiasmando a própria realização agrícola segundo SCHILLING (5).

No período de 1920 e 1936, com exceção da cultura do arroz organizada em moldes capitalistas (lavoura desenvolvida com aplica ção de capitais, liberação de mão-de-obra, uso de tecnologia e inten sificação da produção buscando a geração de divisas), as demais cuI turas, inclusive o trigo, eram lavouras exclusivamente coloniais. Entendendo-se como lavouras coloniais as chamadas tradicionais onde 
a produção das culturas è obtida de forma rudimentar sem exigências de investimentos de capitais e sem adequação às condições ecológicas das àreas.

Apōs 1936, estendendo-se até 1955, a lavoura gaūcha alcan ça um grande progresso atravēs da lavoura capitalista que ampliou os indices de produtividade das culturas de trigo, milho e arroz.

0 ano de 1955 determinou o inicio que marcou o processo de industrialização do Paỉs e no extremo-sul provocou o surgimento da lavoura capitalista em novas bases (empresarial).

o setor agrícola do Rio Grande do Sul não teve condições de servir diretamente ao tipo de industrialização instalada no cen tro do Brasil, como tambēm não teve sua produção absorvida no Esta do dada a inexistência de um processo industrial de vulto. Não hou ve, portanto, a transferência do grosso da comercialização para a sustentação das atividades não-agrícolas. A produção do setor agrí cola, não sendo absorvida no contexto industrial, devido ao tipo de industrialização que se estabelece, passou a desempenhar um papel de poupador (com a agricultura de exportação) para que a nível nacio nal fosse possîvel a importação de bens de capital e de insumos bá sicos necessārios ao desenvolvimento da economia nacional como um todo.

Por tudo isto, costuma-se analisar, neste período, o setor agrícola cumprindo um papel, uma função a nîvel nacional.

A fase pōs-1955, considerada como ēpoca de crise na agro pecuāria gaūcha, ē marcada pelo aparecimento de um terceiro segmen to produtivo como forma de ajustamento ao modelo econômico nacional, a lavoura empresarial, acompanhando a nova fase industrial estabel $\underline{e}$ cida a nível de economia nacional. Este terceiro segmento surgiu co mo alternativa diante dos segmentos pecuária tradicional e agrope cuāria colonial.

A lavoura empresarial ressurginte passa a desempenhar du pla função: 1) a função especîfica de absorver as tecnologias indus triais geradas pelo setor não-agrícola e liberar mão-de-obra para o meio urbano-industrial; 2) a função de poupadora e geradora de divi sas para o conjunto da economia nacional.

Este tem sido o desempenho do setor agrícola gaūcho nos ūltimos anos, podendo-se dizer que o Rio Grande do Sul tem cumprido uma função histōrica, ao adotar a modernização no setor agrīcola,pas sando a colaborar e a permitir que o processo de industrialização se realize.

ASPECTOS QUE MARCAM A EVOLUÇÃO DA EXPLORAÇÃO AGRARIA GADCHA

A evolução da exploração agrícola do Rio Grande do Sul apre 
senta aspectos marcados por crises no setor agrícola que correspon dem às fases de desestruturação da economia e permitem detectar in terferēncias externas que se fizeram sentir.

Para MULLER (1) a evolução do setor agrīcola gaūcho pode ser periodizada em ciclos que espelham fases de estruturação, deses truturação e reestruturação econōmica.

A ocorrēncia de crises no setor agrícola e a detectaçãode ciclos ascendentes e descendentes na economia estadual evidencia a presença de uma ārea central (dominante), constituída por um setor não-agrīcola que intervēm numa ārea periférica (dependente), forma da por um setor agrícola. As relações de interdependência além de sugerirem comparações entre äreas geo-econômicas diferenciadas entre si, que levam, por extensão, à diferenciação de regiões, também per mitem a observação de aspectos que acompanharam a evolução agrícola do Estado, marcando todas as fases de exploração do setor:

- O setor agrícola do Rio Grande do Sul evoluiu em base a um sistema de exploração agrícola que teve como características fun damentais a propriedade da terra, o trabalho familiar e o emprego de atividades diversificadas para os tipos de cultivos e de cria ção desenvolvidos, determinando uma economia, a grosso modo, social mente bem equilibrada.

- A produção agrícola, desenvolvida na paisagem da pecuá ria gaūcha, Campanha, teve sentido tão somente de subsistência prō pria. Na paisagem das colōnias, a terra, diretamente explorada pela famīịa, assume o sentido de sobrevivência e comércio.

Estes aspectos marcariam uma fase de evolução da explora ção do setor agrícola do Estado. chamado por MULLER (1) de "perỉodo Prē-Contemporāneo". A tipificação da atividade do setor ē de uma ärea periférica e dependente do conjunto da economia nacional.

- Até 1945, perīodo da Segunda Grande Guerra, as forças que realizam a interdependēncia do centro (moderno) com a periferia (tradicional) não vão se destacar devido ao desenvolvimento de forças pro dutivas que estão ocorrendo no âmbito nacional e, de modo particu lar, no sul.

0 aspecto marcante é o progresso no quadro da agricultura gaūcha, com o desenvolvimento da lavoura capitalista, representada pela lavoura de arroz que depois juntou a si a lavoura de trigo.

- A crise gerada na lavoura de trigo e arroz faz com que na fase de 1955 a 1964 ocorra a ascenção do movimento popular, no qual os trabalhadores rurais começaram a se organizar.

- o período que vai de 1960 a 1970 corresponde a uma épo ca que, diante da crise gerada (por volta de 1954), determina uma economia para o Estado voltada para o mercado interno de âmbito na 
ciona 1, dependendo do desempenho do setor exportador e exposta a con junturas depressivas, proporciona ao conjunto do Estado certa resi $\underline{s}$ tência frente às crises que tem envolvido a economia nacional.

- o Rio Grande do sul, hoje, está vinculado como economia subsidiāria às atividades do centro do País permanecendo a tarefa de auxiliar o crescimento brasileiro enquanto exerce a função de produ tor de matērias-primas.

A pecuāria e a lavoura ao se definirem como empresariais, estruturando a resistēncia do Estado e usando intensivamente meios de produção, se constituem em mercado para as máquinas, implemen tos, adubos, fertilizantes e insumos químicos, em geral, produzidos pelo setor urbano-industrial da economia nacional.

0 desenvolvimento da lavoura empresarial de trigo e soja em ārea colonial desempenha, alēm da função de poupadora e geradora de divisas, a de procriadora do custo de reprodução da força de tra balho em benefício do setor urbano-industrial.

Desta forma, a expansão da dominação do Centro e sua pene tração na periferia provocou o surgimento de formas de convivência em que as āreas coloniais hä muito estariam perdendo suas caracte rísticas tradicionais, de produtoras de cultivos coloniais e mante nedoras de um hābito de uso da terra, para assimilar um processo de produção agrária e de trabalhar a terra tecnicamente mais modernos.

Este novo processo seria traduzido, na prätica das ativi dades agropecuārias, pela melhoria das condições e demonstração de um novo estāgio emergente nas relações do sistema sōcio-econōmico em que o processo produtivo interferiu no aumento da produção e da pro dutividade deixando, contudo, de envolver uma parcela da população ocupada nas atividades agrārias.

\section{CONSIDERAÇOES FINAIS}

Sob condições histōricas e ambientais especīficas, o Rio Grande do Sul conheceu o desenvolvimento da agropecuāria e tem sido berço de importantes lavouras. Estas têm contribuido se não para um superavit, pelo menos procuram manter o equilíbrio da macroeconomia.

Hoje, no Estado, inūmeras transformações tanto de estrutu ra como de conjuntura vem alterando a organização espacial:

- Hā, em consequēncia do esgotamento da fronteira agríco 1a, uma tendência à concentração da propriedade da terra cujo aces so tem se realizado mediante o arrendamento.

- A lavoura empresarial expande-se por zona cujas caracte rísticas físicas adequam-se à produção tipo empresarial (āreas de topografia suave e de grande dimensão), instalando-se o processo de modernização que, por sua vez, permite a concentração do uso da tér ra. 
- Em āreas de topografia ondulada (predomīnio dos minifún dios) prevalecem métodos tradicionais que revelam carência de recur sos, inadequação dos solos e impossbilidade de sobrevivência com exỉ gua renda.

- Alterações de conjuntura na organização espacial do "Ve Tho Rio Grande", são detectadas atravēs do crescente número de as salariados e de movimentos de deslocamento por migrações. A formação dos sindicatos e das cooperativas sendo resultantes destas transfor mações sociais, passam a ser responsāveis pela introdução de muitas mudanças que estão acelerando a difusão de tēcnicas modernas e a evolução da lavoura empresarial.

A substituição da produção agropecuāria tradicional por uma produção agropecuāria moderna tem acionado no Rio Grande do Sul um novo estägio econômico na evolução de sua exploração agrícola.

B IBL I OGRAF I A CITADA

1. MÜLLER, Geraldo. Periferia e Dependência Nacional: estudo do de senvolvimento do capitalismo no Rio Grande do sul. São Paulo, Tese de Mestrado - Faculdade de Filosofia, Ciências e LetrasUSP (datilografado), 1972.

2. PRADO JUNIOR, Caio. História Econômica do Brasiz. São Paulo, Bra siliense, 1977.

3. RIO GRANDE DO SUL. 25 anos de Economia Gaúcha.Porto Alegre, FEE, Vo1. 2 e 3, 1978.

4. RoCHE, Jean. A Colonizacão Alemã e o Rio Grande do Suz. PortoAle gre, Editora Globo, Vol. I e II, 1969.

5. SCHILLING, Paulo R. Crise Econômica no Rio Grande do Sul: a cri se agropecuária. Porto Alegre, Difusão de Cultura Técnica, 1961.

Recebido em agosto, 1983; aceito em outubro, 1983. 